ESTUDOS REEP

\title{
Demandas de docentes do ensino superior para a formação de alunos com deficiência*
}

Ani Martins Silva

Raquel Cymrot

Maria Eloisa Famá D’Antino

* A pesquisa que deu origem a este trabalho recebeu apoio do Fundo Mackenzie de Pesquisa e contou com a colaboração das pesquisadoras Dra Beatriz Regina Pereira Saeta e $\mathrm{Dr}^{\mathrm{a}}$ Gina Valbão Strozzi e das alunas Arlete Jordano, Azenath Clarissa Arcoverde Gomes e Cyntia Moraes.

\section{Resumo}

Tematiza a inclusão, no ensino superior, de graduandos com deficiência, com vista a oferecer subsídios para a implementação de ações afirmativas e política institucional favorecedoras do aprimoramento das condições de permanência desse alunado na universidade. Foca a investigação no mapeamento e análise das demandas didáticopedagógicas do corpo docente de uma universidade particular paulista, para atender às demandas pedagógicas específicas do corpo discente com deficiência. Os dados foram coletados em dois campi da universidade, por meio de questionário, e posteriormente tabulados, consolidados e analisados (análise estatística e descritiva). Os resultados apontam para a necessidade de se instituir um serviço de apoio à comunidade que possa congregar as ações existentes, mas que se encontram dispersas, em especial aquelas relativas à inclusão social baseada em atitudes favoráveis à diversidade humana.

Palavras-chave: ações afirmativas; ensino superior; graduando com deficiência; inclusão; demandas docentes. 


\section{Abstract \\ Demands of higher education teachers for the formation of students with disabilities}

This article emphasizes the inclusion of disabled students in higher education, with the intend to offer subsidies for the implementation of affirmative actions and politics institutional in favor of the excellence of the conditions of continuity in the university of that student. It focuses also the investigation in the application and analysis of the didactic-pedagogic demands of the faculty of a private university from São Paulo to assist specific pedagogic demands of the disabled student body. The data were collected at two campuses of the university, by a questionnaire and, later, they were tabulated, consolidated and analyzed (statistical and descriptive analysis). The results appear to the emerging need to institute a service of support to the community that can congregate actions, but they find themselves dispersed, especially those in relation to the social inclusion that is based in favorable attitudes to the human diversity.

Keywords: higher education; disabled students; inclusion; educational demands

\section{Introdução}

As políticas públicas brasileiras nos âmbitos federal, estadual e municipal, na esteira de orientações e propostas mundiais, estão marcadas, especialmente a partir da última década do século passado, pela narrativa da educação inclusiva.

[...] é, hoje, o tema mais candente das políticas educacionais em todo o mundo. Isso fica evidente quando constatamos a sua incidência nas grandes propostas políticas nacionais e internacionais, no discurso das políticas de todas as matrizes ideológicas, nas ações concretas dos governantes e de muitas escolas (ou de todas, mesmo que obrigadas), nas produções científicas, acadêmicas e de cunho técnico-profissional (Bueno, 2008, p. 43).

Em se tratando de aluno com deficiência, as perspectivas de investigação expressas nas produções acadêmicas brasileiras denotam que a ênfase tem recaído sobre a educação básica, com incipientes trabalhos sobre a inclusão desse aluno no ensino superior, o que pode indicar, sobretudo, a carência de políticas públicas que avancem para uma educação inclusiva nesse nível de ensino (Moreira, 2005). 
Pacheco e Costas (2005) afirmam que os estudos realizados sobre acesso e permanência de estudantes com necessidades especiais nas Instituições de Ensino Superior (IES) do Brasil demonstram que as iniciativas são isoladas e insuficientes no sentido de lhes proporcionar apoio psicopedagógico para atender suas demandas.

Para Castanho e Freitas (2005), todos os contextos educacionais, entre os quais as IES, são responsáveis pela promoção da cidadania e, como tal, têm o dever de oportunizar e incentivar a educação para todos. A este respeito, é possível estender a reflexão um pouco mais além, pois, nos dias atuais, os professores universitários e os demais envolvidos com esta etapa de ensino formal não podem mais se omitir do envolvimento com o novo paradigma da educação, dado que o reconhecimento e a valorização da diversidade humana, na qual se encontram as pessoas com algum tipo de deficiência, são princípios da educação nacional.

Com vista a contribuir com as investigações sobre a inclusão de graduandos com deficiência na universidade, este artigo apresenta os resultados de pesquisa focada em um dos polos inerentes ao processo de ensino-aprendizagem - as demandas do corpo docente diante da diversidade do alunado com deficiência física, visual, auditiva ou múltipla que tem progressivamente acessado o $3^{\circ}$ grau do ensino.

O recorte temático faz-se necessário por sua abrangência e complexidade, porém, embora centrado nas demandas de professores, o tema é circunscrito pelas autoras deste estudo em uma perspectiva crítica, pois assumem que as políticas de inclusão educacional/escolar devem ser compreendidas como uma das expressões das políticas de inclusão social que, em si, se mostram contraditórias quando se tomam os contextos econômico e social em que têm sido produzidas, qual seja o sistema capitalista vigente, contradições essas evidenciadas por Patto (2008) em análise da relação inclusão/exclusão no sistema capitalista quanto à educação.

No conjunto dos dispositivos legais produzidos a partir da Constituição Federal de 1988 e de seus desdobramentos discursivos, sinaliza-se para o rompimento com uma trajetória histórica marcada pela exclusão das pessoas com deficiência em defesa e garantia de direitos de cidadania, narrativa das políticas educacionais extensivas a outros segmentos da população brasileira alijados de direitos fundamentais.

Se os avanços na área jurídica devem ser reconhecidos, há de se considerar, entretanto, que esses, por si sós, não alteram a realidade social, caracterizada por posições divergentes e práticas contraditórias no interior de instituições educacionais autodenominadas "inclusivas".

O debate está posto pelas políticas educacionais em curso, cabendo às universidades ampliar sua produção e difusão de conhecimentos, informando à comunidade suas práticas com os graduandos com deficiência que a ela têm acessado. Se por força da legislação as barreiras arquitetônicas têm sido enfrentadas paulatinamente, há de se investigar possíveis barreiras de outra natureza vivenciadas pelo corpo docente, dificultadoras da permanência do graduando, explicitando, desse modo, 
o papel por ela cumprido no processo de inclusão universitária da ínfima parcela de graduandos com deficiência que tem atingido o $3^{\text {a }}$ grau após ter vencido a seletividade da educação básica.

No que toca à acessibilidade de estudantes com deficiência nesse nível de ensino, os requisitos estão dispostos na Portaria no 3.284/2003, do Ministério da Educação, definidos para instruir os processos de autorização e reconhecimento de cursos e de credenciamento de instituições de ensino superior; ainda em conformidade com a Norma Brasil 9050, da Associação Brasileira de Normas Técnicas (ABNT, 2004), essa mesma Portaria define as condições básicas de acesso, de mobilidade e de utilização de equipamentos e instalações das instituições, considerando as diferentes naturezas das deficiências.

Se o enfrentamento de barreiras de edificações, de espaços, de mobiliários e equipamentos, extensivas aos espaços urbanos em geral, está assegurado pela legislação, o seu provimento, em si, não se traduz automaticamente no enfrentamento de barreiras de outra natureza implicadas diretamente no processo de ensino-aprendizagem, como constatado em investigações que tematizaram a inclusão de alunos com deficiência no ensino superior.

Moreira (2003, 2005), com vista a colaborar com a efetivação de uma política institucional na Universidade Federal do Paraná, apresentou em 1997 um projeto de ensino, pesquisa e extensão produzido pelo Grupo de Trabalho sobre a Pessoa com Necessidades Especiais, organizado por solicitação da Pró-Reitoria. O projeto propunha-se a acompanhar o processo de ingresso, acesso e permanência do aluno com deficiência na UFPR, e, para tal, fez-se necessário, inicialmente, conhecer a realidade da Instituição referente à demanda.

O mapeamento da demanda, realizado por meio de entrevistas com os coordenadores dos cursos, revela que, no período de 1997 a 1999, a UFPR tinha em seu corpo discente 31 alunos com deficiências, sendo $66 \%$ com deficiência física, 19\% com deficiência auditiva e 15\% com deficiência visual.

A importância de discutir, intervir e viabilizar uma política institucional de inclusão desses alunos, dadas as dificuldades encontradas, foi apontada por 95\% dos coordenadores, inclusive com o encaminhamento de sugestões referentes ao contexto institucional; assim, discussão e intervenção foram consideradas irrelevantes por $5 \%$ dos coordenadores, sendo negadas, portanto, possíveis especificidades da demanda a serem levadas em conta na permanência na Universidade e para o ingresso dos estudantes.

As coordenações apontaram, ainda, dificuldades relacionadas ao desconhecimento da temática pela comunidade universitária, admitindo a existência de preconceitos e discriminações da demanda; dificuldades relacionadas às barreiras arquitetônicas; ausência de assessoramento ao aluno com deficiência e aos professores por parte de profissionais capacitados, aptos a auxiliá-los na organização de metodologias de trabalho e no encaminhamento didático-pedagógico - "não sabemos por onde 
começar", afirmou um dos coordenadores. A conclusão do estudo aponta a importância de organizar no ensino superior serviços e/ou programas institucionais de apoio à demanda dos graduandos com deficiência, que possam colaborar na troca de experiências e viabilizar estratégias e procedimentos educativos mais consonantes com a tão propalada igualdade de oportunidades (Moreira, 2003, p. 88; Moreira, Michels, Colossi, 2006).

No que toca à formação de recursos humanos, há de se registrar avanços nos cursos de licenciatura em geral, nos cursos ligados à área de saúde, de serviço social e demais cursos superiores, com a recomendação do Ministério da Educação para a inclusão da disciplina Aspectos ÉticoPolítico-Educacionais da Normalização e Integração da Pessoa Portadora de Necessidades Especiais ou de conteúdos ligados à Educação Especial (Portaria no 1.793/94) e a inclusão da Língua Brasileira de Sinais (Libras) como disciplina obrigatória nos cursos de formação de professores para o exercício do magistério em nível médio e superior e nos cursos de fonoaudiologia de instituições de ensino públicas e privadas, do sistema federal e dos sistemas de ensino dos Estados, do Distrito Federal e dos Municípios (Decreto no 5.626/2005).

Tais iniciativas são relevantes e necessárias, considerando que, em investigações sobre as ações docentes junto às pessoas com deficiência, tem sido constatada a dificuldade de promover aprendizagens e participação (Vitaliano, 2002; Beyer, 2003, 2006).

A literatura tem apontado iniciativas voltadas à capacitação de professores, particularmente daqueles que atuam no ensino fundamental. Nessas pesquisas, e em outras (Eidelwein, 2005; Jesus, 2006; Martins, 2006), encontram-se indicações de que as universidades deveriam desenvolver, em seus cursos de graduação e pós-graduação e em programas de formação continuada, a preparação de professores e profissionais da educação para atuarem em face da diversidade. Nas universidades, os professores que atuam nos cursos de formação de professores, os denominados de licenciatura, também não estão preparados (Vitaliano, 2002; Rodrigues, 2004; Eidelwein, 2005; Castanho, Freitas, 2005; Pacheco, Costas, 2005; Beyer, 2006).

Nesta direção tem-se a pesquisa realizada por Michels e Dellecave (2005), que analisaram as condições de oferta do ensino inclusivo em uma universidade localizada em Santa Catarina, na perspectiva dos professores que tinham alunos com deficiência e com necessidades educacionais especiais em sala de aula. As análises das entrevistas empreendidas com os professores indicaram que eles necessitam de mais subsídios que possam garantir a qualidade da prática inclusiva, pois relataram muitas dificuldades referentes à seleção de estratégias de ensino e de avaliação ao lidar com o aluno com necessidades educacionais especiais em sala de aula. As autoras concluíram que os educadores devem se conscientizar do seu papel no processo inclusivo, pois são eles que mediam as relações do processo de ensino-aprendizagem, afastando preconceitos e contribuindo com um ensino de qualidade.

Para tanto, novos desafios se impõem aos professores universitários, cabendo-lhes envolver-se com o novo paradigma da educação, dada a 
crescente presença da diversidade humana no interior das instituições de ensino superior, requerendo, por vezes, recursos e apoios especializados, além de atitudes de abertura à convivência com as diferenças, pois "os preconceitos e significações a respeito do diferente e do deficiente precisam ser repensados e trabalhados [...]" (Ferreira, 2003, p. 272).

Assim, projetar uma universidade inclusiva envolve, além de mudanças físicas e administrativas, o enfrentamento, por todos, de barreiras atitudinais, reconhecendo a existência das diferenças e, principalmente, valorizando-as. Trata-se de um processo complexo e gradativo, porém é o caminho possível para reduzir o hiato entre o discurso teórico, os dispositivos legais e as práticas, considerações cabíveis a qualquer nível de ensino.

Um ensino de qualidade deve estar disponível para todos os indivíduos que desejam ascender a um patamar mais elevado no processo educacional; por isso, devem ser utilizados todos os recursos disponíveis que tornam o acesso à informação possível, inclusive os profissionais que trabalham em bibliotecas universitárias, que devem ser formados para participar do processo de inclusão de alunos com deficiência. Só assim as barreiras de acesso à informação serão derrubadas (Paula, Carvalho, 2009).

Nesse sentido, espera-se que aos graduandos com deficiência sejam oferecidas condições a partir das quais eles possam manifestar seu potencial acadêmico, o que passa necessariamente pela ressignificação das atitudes ante as diferenças expressas nas ações, interações, sentimentos e comportamentos vivenciadas pelo corpo docente no enfrentamento de questões e inquietações relacionadas à diversidade humana, entre essas as diferenças marcadas pela deficiência, a fim de que possam atuar como facilitadoras da permanência desse graduando no ensino superior.

Se a legislação e o discurso docente se tornaram "inclusivos", cabe investigar as práticas, pois "[...] é preciso não invocar o nome da inclusão em vão, tentando 'mapear' esta distância entre os discursos e as práticas" (Rodrigues, 2006, p. 302).

Sem negar a relevância do papel dos coordenadores de cursos e diretores das unidades acadêmicas, propõe-se neste estudo uma investigação centrada no corpo docente de uma universidade particular na cidade de São Paulo, denominado nesse artigo como Universidade Alvo (UA), conhecendo suas demandas, que, uma vez mapeadas e analisadas, poderão oferecer subsídios aos seus dirigentes para a implementação de ações afirmativas e política institucional favorecedoras do aprimoramento das condições de permanência desse alunado.

\section{Procedimentos metodológicos}

A pesquisa foi realizada entre 2009 e 2010, por meio de levantamento de dados em dois dos campi da UA.

A coleta de dados foi iniciada após a entrega da Carta de informação à Instituição e assinatura do Termo de Consentimento Livre e 
Esclarecimento, pela reitoria, com prévia aprovação pelo Comitê de Ética e Pesquisa com Humanos da Universidade.

O instrumento de coleta de dados, questionário especialmente elaborado pelas pesquisadoras para essa finalidade, foi composto por 11 questões fechadas e uma aberta, e as variáveis de interesse contempladas foram: gênero do professor; faixa etária; área principal de formação; unidade universitária de origem; localização do campus de sua unidade de origem; cursos nos quais o professor leciona; tempo de docência no ensino superior e na universidade, em faixas; experiência ou não com aluno com deficiência, tanto no ensino superior como nos últimos quatro anos na universidade; tipo de deficiência do aluno para o qual leciona (física, auditiva e visual); se leciona para aluno com outra condição essencial não referida à deficiência e, em caso afirmativo, qual/is a/as condição/ões apresentadas pelo aluno. Outras variáveis contempladas foram as necessidades de natureza diversa que o aluno com deficiência pode ter e as condições diferenciadas para o atendimento às demandas específicas e essenciais do aluno com deficiência física, visual e auditiva, facilitadoras de sua permanência na universidade. Por fim, e em questão aberta, foi solicitado ao professor que especificasse o/s tipo/s de apoio que a universidade poderia oferecer para melhor atender as demandas do aluno com deficiência.

Os questionários foram disponibilizados em locais de assinatura de ponto dos professores, com anotação, pelo próprio professor, da data de recebimento e de entrega, em envelope individual e sem identificação. Tal procedimento garantiu o anonimato de resposta e o não constrangimento no caso de recusa em participar da pesquisa, uma vez que não foi verificado se o questionário depositado estava ou não preenchido. No corpo do questionário foi solicitada a sua devolução, ainda que em branco, tornando seu preenchimento, desta forma, facultativo.

O questionário foi respondido por 752 professores (53,9\%), entre os 1.394 existentes nos dois campi da instituição. A amostra resultante não pode ser considerada probabilística, porém foi criteriosa, uma vez que o critério de amostragem foi objetivo, com seu protocolo descritivo inequívoco, produzindo amostras com as mesmas propriedades, independentemente de quem as selecionou (Bolfarine, Bussab, 2005).

Após a coleta, os dados foram tabulados e consolidados, e, a fim de verificar a consistência interna das respostas obtidas, foi calculado o coeficiente alfa de Cronbach. Um coeficiente superior a 0,70 é considerado aceitável na maioria das situações de pesquisa (Reis, Ferreira, 2000).

A seguir foi realizada uma análise descritiva dos dados, por meio de construção de gráficos e tabelas, bem como do cálculo de estatísticas, como média, desvio padrão, coeficiente de variação, quartis, mínimo e máximo.

Foram realizados testes de independência entre pares de variáveis aleatórias pertinentes, utilizando-se o teste Qui-quadrado, uma vez respeitadas as suposições para seu uso. Quando a tabela, após agruparem-se linhas e colunas, resultou 2 × 2, de modo a ainda não satisfazer as condições de uso do teste Qui-quadrado, utilizou-se o teste Exato de Fisher (Siegel, Castellan Junior, 2008). 
Para testar se as notas médias atribuídas às necessidades de natureza diversa do aluno com deficiência foram as mesmas, utilizou-se o teste não Paramétrico de Friedman (Siegel, Castellan Junior, 2008).

Todos os testes de hipótese foram realizados com nível de significância de 5\%, sendo seus respectivos níveis descritivos (valor-P) calculados. Foram rejeitadas, portanto, as hipóteses cujos níveis descritivos resultaram menores que 0,05.

A análise dos dados foi realizada com a utilização do programa Minitab®.

\section{Apresentação e discussão dos dados}

A universidade congrega em dois de seus campi nove unidades universitárias, entre centros e faculdades, totalizando 27 cursos de graduação e nove programas de pós-graduação.

Foram distribuídos nos dois campi 1.394 questionários, de acordo com o número de professores por unidade informado pelos recursos humanos da instituição, e, destes, apenas 752 foram respondidos, o que equivale a uma amostra de 53,9\% dos professores.

\section{Caracterização dos docentes}

Na análise dos dados, no que toca à caracterização da amostra por gênero e faixa etária, tem-se 275 professores do sexo feminino e 465 do sexo masculino, correspondendo a 740 professores, pois 12 professores não informaram o sexo. A predominância masculina se evidencia, com $62,8 \%$ (465) homens e 37,2\% (275) mulheres. Trata-se de um grupo relativamente jovem (Gráfico 1).

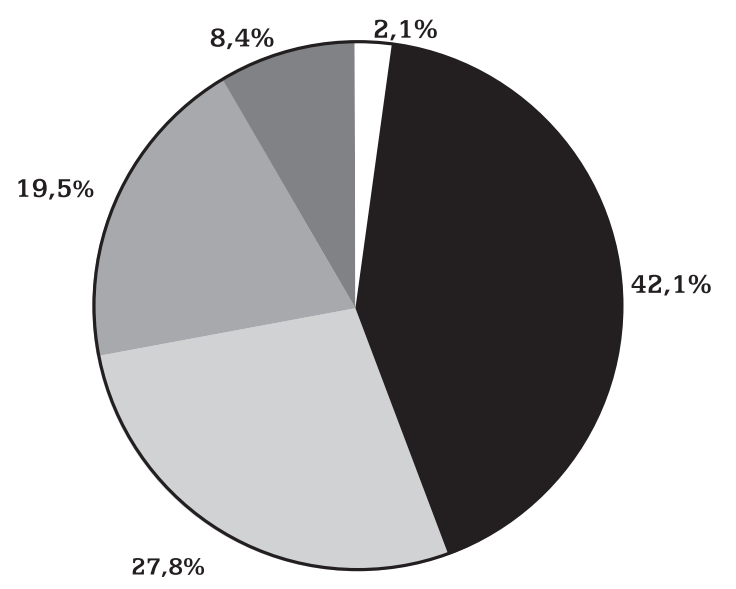

\section{Categoria}

$\square$ até 30 anos

$\square$ de 31 a 45 anos

de 46 a 55 anos

de 56 a 65 anos

mais de 65 anos

Gráfico 1 - Caracterização dos Docentes por Faixa Etária 
Dos 748 professores que informaram sua faixa etária, 2,1\% (16) têm até 30 anos; 42,1\% (315) estão na faixa de 31 a 40 anos; somados estes percentuais, temos $44,2 \%$ (331) da amostra com até 40 anos. Na extremidade etária, de 51 a 70 anos, há 19,5 (146) com até 60 anos e 8,4\% (63) entre 61 e 70 anos. Portanto, têm-se 27,9\% ou 209 professores nos dois últimos intervalos etários, percentual coincidente com a faixa média de idade, pois $27,8 \%$ (208) dos professores informaram ter entre 41 e 50 anos de idade.

Na caracterização da amostra por área de formação, foram obtidos os dados expressos no Gráfico 2.

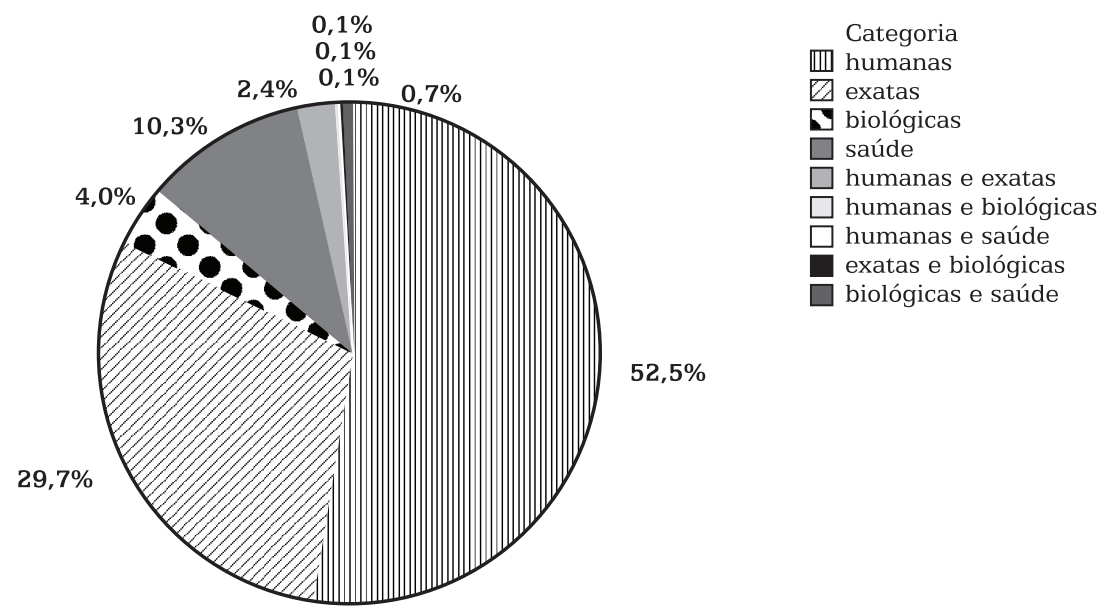

\section{Gráfico 2 - Perfil dos Docentes por Área de Formação}

A formação predominante recaiu na área de ciências humanas, com 394 professores $(52,5 \%)$, seguida das de exatas, com 223 professores (29,7\%), de saúde, com 77 (10,3\%), e biológicas, com 30 (4,0\%). Há 26 professores $(3,4 \%)$ com formação em duas áreas: $18(2,4 \%)$ nas de humanas e exatas, $5(0,7 \%)$ nas de biológicas e da saúde e $3(0,3 \%)$, respectivamente, nas áreas de humanas e biológicas, humanas e da saúde e exatas e da saúde. Dois dos 752 professores da amostra não informaram sua área de formação.

\section{Docência no ensino superior}

O tempo de docência no ensino superior e na universidade, tomado como variável indicativa de maior ou menor probabilidade de o professor ter trabalhado com graduando com deficiência, está expresso na Tabela 1 e no Gráfico 3.

A caracterização da amostra por tempo de experiência no ensino superior (750 professores) e na UA (565 professores) foi assim configurada: no máximo há 5 anos, com 59 professores (7,9\%) no ensino superior e $200(35,4 \%)$ na UA, sendo possível portanto inferir que, destes últimos, 
141 trabalham apenas na UA; entre 6 e 10 anos de experiência no ensino superior, temos $196(26,1 \%)$ professores do total de 750 (100\%) e 127 $(22,5 \%)$ do total de 565 (100\%) com esse tempo de experiência na UA, ou seja, 69 professores tiveram experiências anteriores à entrada na UA. Essa situação se repete com os que informaram tempo de docência entre 11 e 15 anos - 131 professores (17,5\%) no ensino superior e 45 (8\%) na UA -, bem como para aqueles com mais de 20 anos de experiência - 254 professores (33,9\%) no ensino superior e 137 (24,2\%) na UA.

Tabela 1 - Perfil dos Professores por Tempo de Docência

\begin{tabular}{|l|c|c|c|c|}
\multicolumn{1}{|c|}{ Anos } & \multicolumn{2}{|c|}{ No Ensino Superior } & \multicolumn{2}{c|}{$\begin{array}{c}\text { Na Universidade } \\
\text { Alvo (UA) }\end{array}$} \\
\hline Até 5 & 59 & $(7,9 \%)$ & 200 & $(35,4 \%)$ \\
\hline De 6 a 10 & 196 & $(26,1 \%)$ & 127 & $(22,5 \%)$ \\
\hline De 11 a 15 & 131 & $(17,5 \%)$ & 45 & $(8,0 \%)$ \\
\hline De 16 a 20 & 110 & $(14,7 \%)$ & 56 & $(9,9 \%)$ \\
\hline Mais de 20 & 254 & $(33,9 \%)$ & 137 & $(24,2 \%)$ \\
\hline \multicolumn{1}{|c|}{ Total } & $\mathbf{7 5 0}$ & $\mathbf{( 1 0 0 \% )}$ & $\mathbf{5 6 5}$ & $\mathbf{( 1 0 0 \% )}$ \\
\hline
\end{tabular}

\section{tempo no ensino superior}

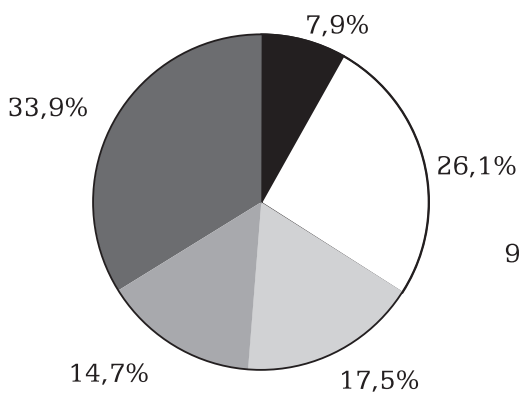

tempo na UA

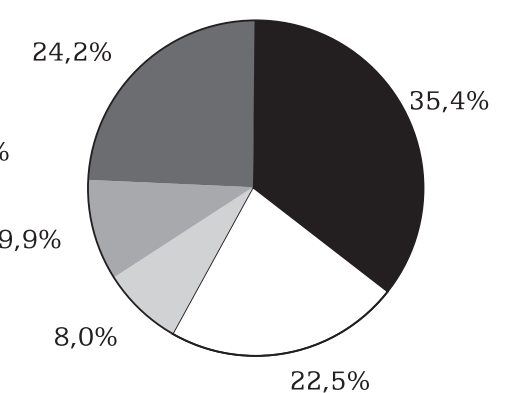

$22,5 \%$
Categoria menos de 5 anos $\square$ de 5 a 10 anos de 11 a 15 anos de 16 a 20 anos mais de 20 anos

\section{Gráfico 3 - Perfil dos Professores por Tempo de Docência}

Cabe relembrar que estes percentuais não expressam a totalidade do corpo docente dos campi aqui considerados e, também, que apenas 565 professores, dos 752 que responderam o questionário, informaram o tempo de trabalho na UA. Entretanto, considerou-se que o tempo de experiência no $3^{\circ}$ grau de ensino e a demanda ainda reduzida, porém crescente, de graduandos com deficiência poderiam ser correlacionados. Dito de outra forma, a possibilidade de ter tido em suas classes graduandos com deficiência é maior para o professor com mais tempo de experiência no ensino superior e na UA, inclusive com diferentes tipos de deficiência e outras condições especiais. 
Tabela 2 - Experiência do Professor com Graduandos com Deficiência e com Graduandos com Outras Condições Especiais

\begin{tabular}{|c|c|c|c|c|c|c|c|c|c|c|}
\hline \multirow{2}{*}{\multicolumn{3}{|c|}{ Deficiência }} & \multicolumn{6}{|c|}{ Tipo de Deficiência ${ }^{(1)}$} & \multirow{2}{*}{\multicolumn{2}{|c|}{$\begin{array}{l}\text { Outras Condições } \\
\text { Especiais }\end{array}$}} \\
\hline & & & \multicolumn{2}{|c|}{ DF } & \multicolumn{2}{|c|}{ DA } & \multicolumn{2}{|c|}{ DV } & & \\
\hline \multirow[b]{2}{*}{$\begin{array}{l}\text { Ensino } \\
\text { Superior }\end{array}$} & Sim & Não & Sim & Não & Sim & Não & Sim & Não & Sim & Não \\
\hline & $\begin{array}{c}532 \\
(70,9 \%)\end{array}$ & $\begin{array}{c}218 \\
(29,1 \%)\end{array}$ & $\begin{array}{c}399 \\
(53,5 \%)\end{array}$ & $\begin{array}{c}347 \\
(46,5 \%)\end{array}$ & $\begin{array}{c}229 \\
(30,7 \%)\end{array}$ & $\begin{array}{c}516 \\
(69,3 \%)\end{array}$ & $\begin{array}{c}195 \\
(26,2 \%)\end{array}$ & $\begin{array}{c}550 \\
(73,8 \%)\end{array}$ & $\begin{array}{c}74 \\
(13,8 \%)\end{array}$ & $\begin{array}{c}462 \\
(86,2 \%)\end{array}$ \\
\hline UA & $\begin{array}{c}335 \\
(47,4 \%)\end{array}$ & $\begin{array}{c}394 \\
(52,6 \%)\end{array}$ & $\begin{array}{c}254 \\
(34,3 \%)\end{array}$ & $\begin{array}{c}486 \\
(65,7 \%)\end{array}$ & $\begin{array}{c}116 \\
(15,7 \%)\end{array}$ & $\begin{array}{c}624 \\
(84,3 \%)\end{array}$ & $\begin{array}{c}80 \\
(10,8 \%)\end{array}$ & $\begin{array}{c}660 \\
(89,2 \%)\end{array}$ & $\begin{array}{c}51 \\
(9,8 \%)\end{array}$ & $\begin{array}{c}469 \\
(90,2 \%)\end{array}$ \\
\hline
\end{tabular}

Notas: (1) DF = deficiência física; DA = deficiência auditiva; DV = deficiência visual.

(2) A questão especificava a experiência, na UA, com graduandos com deficiência, nos últimos quatro anos.

O percentual correspondente aos 532 professores do ensino superior que têm experiência com graduandos portadores de deficiência no ensino superior é de, aproximadamente, $71 \%$ dos 750 que responderam à questão, contra 29\% que negaram a experiência. Na UA, por sua vez, 47,4\% (355) dos professores afirmaram essa experiência, contra 52,6\% (394) que a negaram, dados estes ilustrados no Gráfico 4.

\section{deficiência ensino superior}

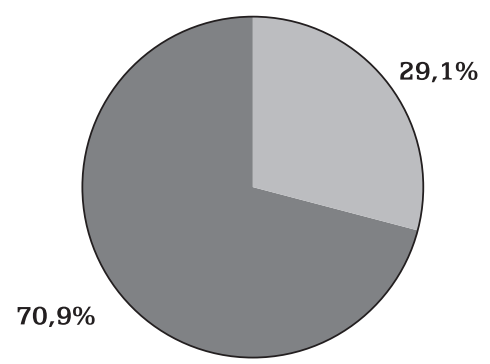

\section{deficiência na UA}

$47,4 \%$

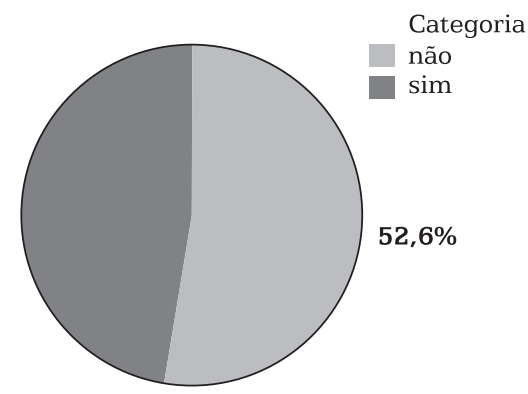

\section{Gráfico 4 - Experiência no Ensino Superior e na UA com Graduandos com Deficiência}

Cabe ressaltar no entanto, quer essa experiência tenha ocorrido em outros espaços institucionais, quer na UA, que os números não são absolutos, ou seja, não correspondem aos de alunos com deficiência, pois estes frequentam, ao mesmo tempo e ao longo do curso, disciplinas diversas com diferentes professores.

\section{O graduando com deficiência e suas demandas, na perspectiva do professor}

Quanto ao tipo de deficiência apresentada pelos alunos com os quais o professor teve experiência, constata-se que: a) no ensino superior, 
do total de 532 professores, $\mathrm{DF}=399(53,5 \%)$ professores, $\mathrm{DA}=229$ $(30,7 \%)$ professores, $\mathrm{DV}=195(26,2 \%)$ professores; b) na UA, do total de 355 professores, $\mathrm{DF}=254(34,3 \%)$ professores, $\mathrm{DA}=116(15,7 \%)$ professores, DV $=80(10,8 \%)$ professores;

A deficiência física tem sido a mais presente no $3^{\circ}$ grau de ensino, seguida das deficiências auditiva e visual, o que é concordante com a incidência do tipo de deficiência na população em geral, exceto a deficiência mental, conforme estimativas da Organização Mundial da Saúde (OMS).

Os Gráficos 5 e 6 ilustram os dados referentes à experiência do professor por tipo de deficiência apresentada pelo aluno, respectivamente, no ensino superior e na UA.

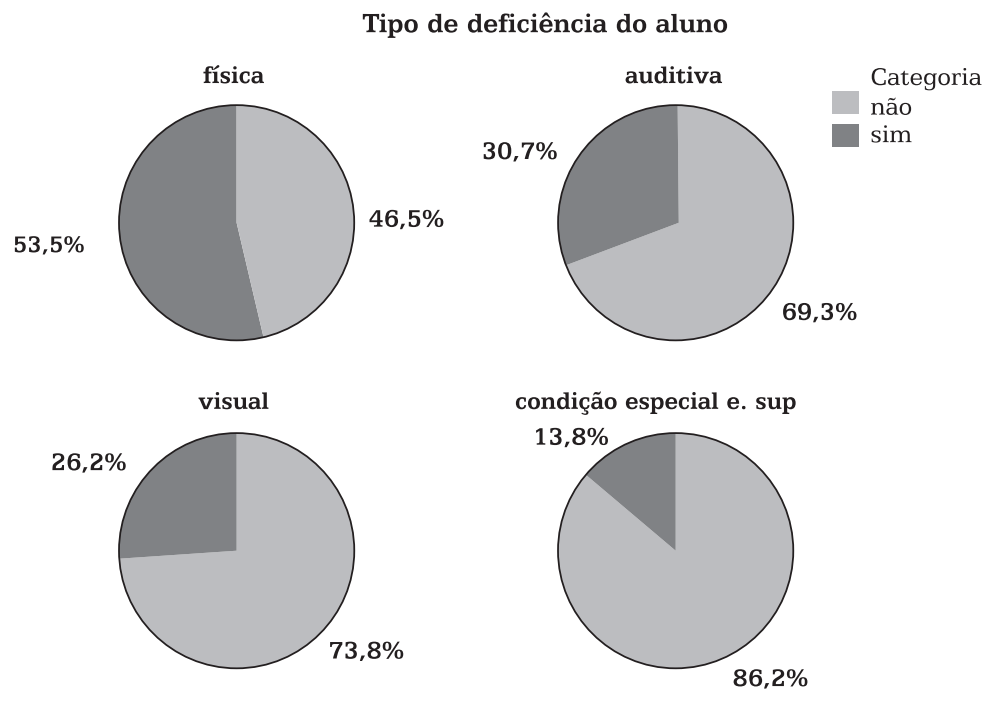

\section{Gráfico 5 - Experiência do Professor e Tipo de Deficiência do Graduando no Ensino Superior}

Tipo de deficiência do aluno na UA
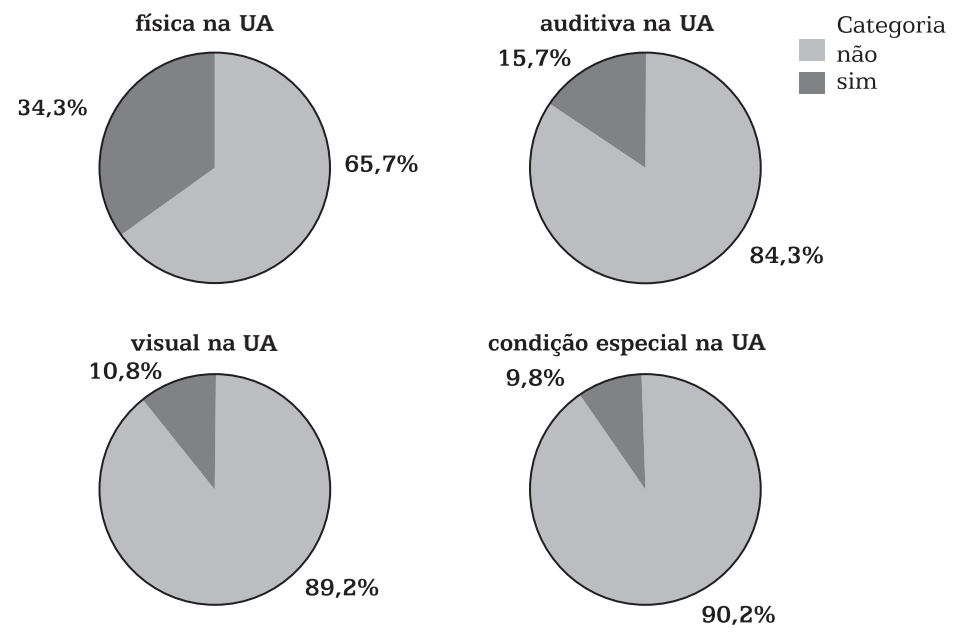

Gráfico 6 - Experiência do Professor e Tipo de Deficiência do Graduando na UA 
Nota-se que a Tabela 2 apresenta dados referentes à experiência do professor com alunos com outras condições especiais que não aquelas relacionadas às deficiências, cujas especificações serão apresentadas posteriormente.

Para medir a consistência interna das respostas obtidas foi calculado o coeficiente alfa de Cronbach para a questão sobre as necessidades de natureza diversa que o aluno com deficiência pode ter (escala de 1 a 5) e para as questões sobre as condições diferenciadas para o atendimento às demandas específicas do aluno com deficiência física, visual e auditiva (escala de 0 e 1). O primeiro resultou igual a 0,7283 e o segundo, igual a 0,8349, ambos superiores a 0,70, considerados aceitáveis, caracterizando que os respondentes pertencem a um mesmo constructo.

Os resultados da avaliação pelo professor (atribuição de notas de 1 a 5) de possíveis necessidades do aluno com deficiência, que na percepção do professor são mais ou menos relevantes, são apresentados na Tabela 3.

Tabela 3 - Relevância às Demandas Gerais do Graduando com Deficiência, na Perspectiva do Professor

\begin{tabular}{|c|c|c|c|c|c|c|}
\hline \multirow{2}{*}{ Necessidade/Aluno } & \multicolumn{5}{|c|}{ Classificação pelo Professor } & \multirow{2}{*}{ Total } \\
\hline & 5 & 4 & 3 & 2 & 1 & \\
\hline $\begin{array}{l}\text { 1) Eliminação de barreira } \\
\text { arquitetônica e } \\
\text { adaptação de espaço } \\
\text { físico. }\end{array}$ & $\begin{array}{c}481 \\
(67,1 \%)\end{array}$ & $\begin{array}{c}60 \\
(8,4 \%)\end{array}$ & $\begin{array}{c}75 \\
(10,5 \%)\end{array}$ & $\begin{array}{c}31 \\
(4,3 \%)\end{array}$ & $\begin{array}{c}70 \\
(9,7 \%)\end{array}$ & $\begin{array}{c}717 \\
(100 \%)\end{array}$ \\
\hline $\begin{array}{l}\text { 2) Adaptação de } \\
\text { mobiliário e } \\
\text { equipamentos em sala } \\
\text { de aula (laboratórios, } \\
\text { bibliotecas...). }\end{array}$ & $\begin{array}{c}315 \\
(43,7 \%)\end{array}$ & $\begin{array}{c}135 \\
(18,7 \%)\end{array}$ & $\begin{array}{c}121 \\
(16,8 \%)\end{array}$ & $\begin{array}{c}69 \\
(9,6 \%)\end{array}$ & $\begin{array}{c}81 \\
(11,2 \%)\end{array}$ & $\begin{array}{c}721 \\
(100 \%)\end{array}$ \\
\hline $\begin{array}{l}\text { 3) Adaptação didático- } \\
\text { pedagógica nos } \\
\text { processos de ensino- } \\
\text { aprendizagem. }\end{array}$ & $\begin{array}{c}241 \\
(33,5 \%)\end{array}$ & $\begin{array}{c}142 \\
(19,7 \%)\end{array}$ & $\begin{array}{c}142 \\
(19,7 \%)\end{array}$ & $\begin{array}{c}85 \\
(11,8 \%)\end{array}$ & $\begin{array}{c}110 \\
(15,3 \%)\end{array}$ & $\begin{array}{c}720 \\
(100 \%)\end{array}$ \\
\hline $\begin{array}{l}\text { 4) Adaptação em } \\
\text { procedimentos de } \\
\text { avaliação do ensino- } \\
\text { aprendizagem. }\end{array}$ & $\begin{array}{c}212 \\
(29,5 \%)\end{array}$ & $\begin{array}{c}123 \\
(17,1 \%)\end{array}$ & $\begin{array}{c}173 \\
(24,1 \%)\end{array}$ & $\begin{array}{c}79 \\
(11,0 \%)\end{array}$ & $\begin{array}{c}132 \\
(18,3 \%)\end{array}$ & $\begin{array}{c}719 \\
(100 \%)\end{array}$ \\
\hline $\begin{array}{l}\text { 5) Eliminação de } \\
\text { barreiras interpessoais } \\
\text { manifestas em ações, } \\
\text { sentimentos e atitudes } \\
\text { preconceituosas em } \\
\text { relação à pessoa com } \\
\text { deficiência, comumente } \\
\text { presentes nos espaços } \\
\text { sociais. }\end{array}$ & $\begin{array}{c}312 \\
(43,3 \%)\end{array}$ & $\begin{array}{c}80 \\
(11,1 \%)\end{array}$ & $\begin{array}{c}127 \\
(17,6 \%)\end{array}$ & $\begin{array}{c}50 \\
(7,0 \%)\end{array}$ & $\begin{array}{c}151 \\
(21,0 \%)\end{array}$ & $\begin{array}{c}720 \\
(100 \%)\end{array}$ \\
\hline
\end{tabular}


Foi testado, por meio do teste não paramétrico de Friedman, se as notas médias atribuídas às necessidades foram todas iguais. Tal hipótese foi rejeitada ( $\mathrm{P}=0,000)$, indicando que as relevâncias apontadas não são as mesmas para todas as necessidades.

Destaca-se na tabela a nota 5 atribuída pelos professores às cinco necessidades que lhes foram apresentadas, cujos percentuais são superiores às demais notas, especialmente a necessidade referente à eliminação de barreira arquitetônica e adaptação de espaço físico ( $1^{\text {a }}$ necessidade), seguida da necessidade de adaptação de mobiliário e equipamentos ( $2^{\mathrm{a}}$ necessidade): $67,1 \%$ (481) e 43,7\% (315) dos professores consideram, respectivamente, essas duas necessidades como muito relevantes. Enquanto 236 professores (32,9\%) atribuíram à $1^{\mathrm{a}}$ necessidade notas entre 1 e 4 , a $2^{\mathrm{a}}$ necessidade teve uma outra distribuição, pois 256 professores $(35,5 \%)$ a qualificaram com notas 3 e 4 e $150(20,8 \%)$ a qualificaram com notas 1 e 2 .

Trata-se de dados importantes para reflexão, pois indicam, a nosso ver, uma disposição positiva, por parte do professor, em reconhecer demandas mais gerais do graduando com deficiência, porém distanciadas do espaço da sala de aula, como laboratórios e bibliotecas ( $2^{\mathrm{a}}$ necessidade), o que parece se confirmar pela avaliação feita às demais necessidades do graduando, em especial a $3^{\mathrm{a}}$ e a $4^{\mathrm{a}}$, que se referem diretamente a ações que remetem à sala de aula.

A necessidade de adaptação didático-pedagógica ( $3^{a}$ necessidade) e em procedimentos de avaliação do ensino-aprendizagem ( $4^{\mathrm{a}}$ necessidade), embora com percentuais de nota 5 superiores às demais notas, a média das notas 5 atribuídas as duas necessidade não atinge $32 \%$ dos que as consideram muito relevantes: 241 (33,5\%) e 212 $(29,5 \%)$, respectivamente (cf. Tabela 3). Para a necessidade $n^{\circ} 4$, a nota $1(18,3 \%)$ é superior à nota $2(11,0 \%)$ e à nota $4(17,1 \%)$, embora $24,1 \%$ dos professores (173) lhe tenham atribuído nota 3. A mesma tendência pode ser observada na avaliação da $3^{a}$ necessidade, com $15,3 \%$ (110) dos professores que lhe atribuíram nota 1, contra 11,8\% (85) com nota 2 , e um mesmo percentual para as notas 3 e $4-19,7 \%$ (142) dos professores.

A necessidade do graduando com deficiência circunscrita à dimensão relacional $\left(5^{\mathrm{a}}\right)$, que implica o enfrentamento pelo grupo social de conteúdos preconceituosos, presentes em ações, sentimentos e atitudes, configuradas como barreiras interpessoais, foi qualificada por $43,3 \%$ (312) dos professores como muito relevante (nota 5), contra 21,0\% (151) dos professores que negam essa relevância (nota 1). Os demais professores, 257 dos 720, assim a qualificaram: 11,1\% (80) com nota $4 ; 17,6 \%$ (127) com nota 3 e 7,0\% (50) com nota 2.

A síntese da média de notas (de 1 a 5) atribuídas a cada necessidade geral pode ser visualizada no Gráfico 7, reafirmando a análise acima.

Cabe retomar que 53,5\% e 34,3\% dos professores (cf. Tabela 2) informaram ter tido, respectivamente, experiência no ensino superior ou na UA com graduandos com deficiência física, o que remete a possíveis 
percepções de necessidades desse grupo, de ordem arquitetônica, de mobiliário e equipamentos, o que poderia explicar a média mais elevada das notas atribuídas à $1^{a}$ necessidade (eliminação de barreira arquitetônica) e à $2^{\mathrm{a}}$ necessidade (adaptação de mobiliário e equipamentos).

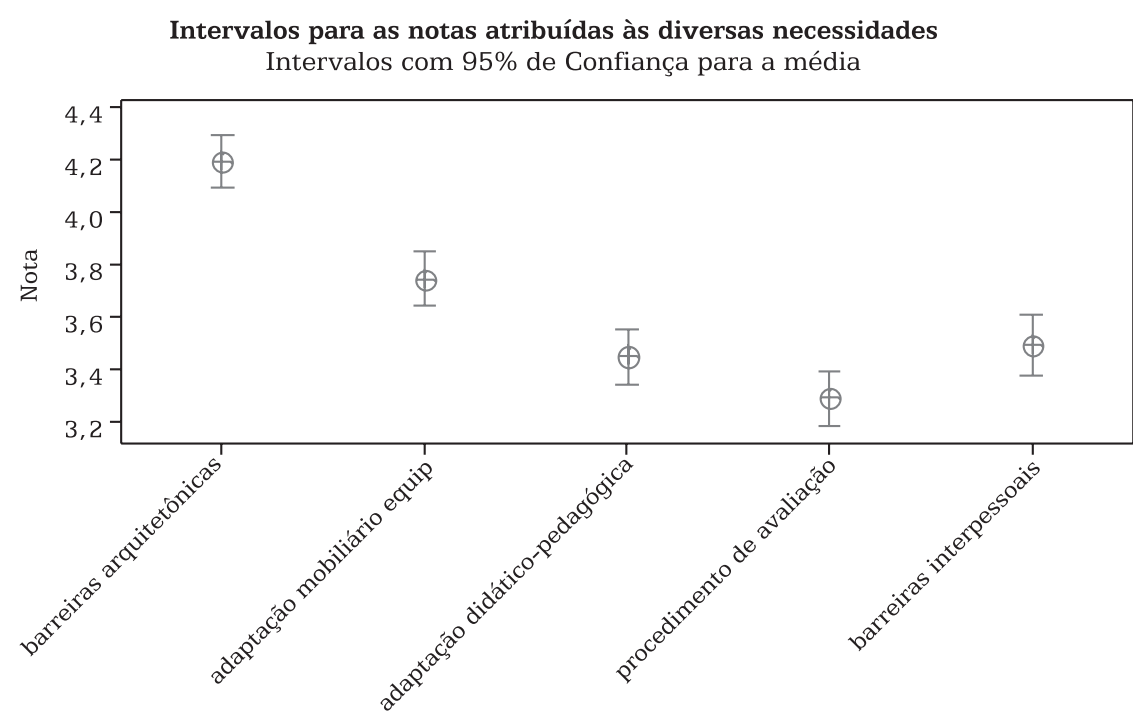

\section{Gráfico 7 - Média de Notas, por Relevância, Atribuídas às Necessidades Gerais do Graduando com Deficiência}

Ao nível de significância de 5\%, afirma-se que as notas atribuídas não são iguais para as cinco necessidades, podendo-se observar que a necessidade eliminação de barreira arquitetônica obteve notas superiores e a necessidade adaptação em procedimentos de avaliação obteve notas inferiores.

No entanto, e embora a questão seja genérica, 30,7\% (229) e 26,2\% (195) dos professores (cf. Tabela 2) informaram ter trabalhado, respectivamente, com graduandos com deficiências auditiva e visual, que, a depender das "perdas" decorrentes da deficiência, requerem adaptações no processo de ensino-aprendizagem ( $3^{\mathrm{a}}$ necessidade) e nos procedimentos de avaliação ( $4^{\mathrm{a}}$ necessidade), principalmente em se tratando de graduando com surdez ou severa deficiência auditiva, necessidades que, juntamente com a eliminação de barreiras interpessoais ( $5^{\mathrm{a}}$ necessidade), foram configuradas como de menor relevância comparativamente às duas primeiras.

Se as necessidades específicas, porém gerais, do "outro" com deficiência, são percebidas e qualificadas como acima apresentadas, cabe agora aproximar-se das condições diferenciadas desse alunado, de suas possíveis necessidades, por tipo de deficiência, cujas demandas estão previstas na legislação brasileira, devendo, desse modo e se necessário, serem atendidas pela instituição educacional como condição para a permanência do aluno na universidade e até mesmo no curso frequentado, a depender do quadro apresentado pelo graduando. 
Assim, foram apresentadas ao professor cinco necessidades, por tipo de deficiência, que foram por ele avaliadas como sendo ou não essenciais para o graduando.

Na sequência, apresentam-se os resultados das respostas dos professores: Tabela 4/deficiência física, Tabela 4A/deficiência auditiva e Tabela 4B/deficiência visual.

Tabela 4 - Graduando com Deficiência Física na Universidade e Atendimento as suas Demandas Específicas, na Perspectiva do Professor

\begin{tabular}{|c|c|c|c|}
\hline \multirow{2}{*}{ Demandas do Graduando } & \multicolumn{2}{|c|}{ Essencial } & \multirow{2}{*}{ Total } \\
\hline & Sim & Não & \\
\hline $\begin{array}{l}\text { 1) Acesso aos espaços de uso coletivo } \\
\text { por meio da eliminação de barreira } \\
\text { arquitetônica. }\end{array}$ & $\begin{array}{c}663 \\
(90,0 \%)\end{array}$ & $\begin{array}{c}74 \\
(10,0 \%)\end{array}$ & $\begin{array}{c}737 \\
(100 \%)\end{array}$ \\
\hline $\begin{array}{l}\text { 2) Reserva de vagas em estacionamentos } \\
\text { nas proximidades da Universidade. }\end{array}$ & $\begin{array}{c}410 \\
(55,6 \%)\end{array}$ & $\begin{array}{c}327 \\
(44,4 \%)\end{array}$ & $\begin{array}{c}737 \\
(100 \%)\end{array}$ \\
\hline $\begin{array}{l}\text { 3) Construção de rampas com corrimão ou } \\
\text { colocação de elevadores para facilitar a } \\
\text { circulação de cadeiras de rodas. }\end{array}$ & $\begin{array}{c}641 \\
(87,0 \%)\end{array}$ & $\begin{array}{c}96 \\
13,0 \%)\end{array}$ & $\begin{array}{c}737 \\
(100 \%)\end{array}$ \\
\hline $\begin{array}{l}\text { 4) Adaptação de portas e banheiros de } \\
\text { forma a permitir o acesso de cadeiras } \\
\text { de rodas, e colocação de barras de apoio } \\
\text { nas paredes dos banheiros. }\end{array}$ & $\begin{array}{c}586 \\
(79,6 \%)\end{array}$ & $\begin{array}{c}150 \\
(20,4 \%)\end{array}$ & $\begin{array}{c}736 \\
(100 \%)\end{array}$ \\
\hline $\begin{array}{l}\text { 5) Instalação de lavabos, bebedouros } \\
\text { e telefones públicos em alturas } \\
\text { acessíveis aos usuários de cadeiras de } \\
\text { rodas. }\end{array}$ & $\begin{array}{c}512 \\
(69,5 \%)\end{array}$ & $\begin{array}{c}225 \\
(30,5 \%)\end{array}$ & $\begin{array}{c}737 \\
(100 \%)\end{array}$ \\
\hline
\end{tabular}

Da amostra de 752 professores, 737 (98\%) responderam à questão, evidenciando nas cinco necessidades, em especial na $2^{\mathrm{a}}$, na $4^{\mathrm{a}}$ e na $5^{\mathrm{a}}$ (cf. tabela), maiores dificuldades do professor em reconhecer direitos e necessidades específicas do aluno com deficiência física: direito de transitar de automóvel adaptado, possível inclusive para o usuário de cadeira de rodas, pois $44,4 \%$ (327) dos professores não avaliam como sendo essencial para esse aluno ter vagas reservadas em estacionamentos nas proximidades da UA. Ainda para o usuário de cadeira de rodas não são considerados essenciais o acesso a lavabos, bebedouros e telefones públicos, conforme $30,5 \%$ (225) dos professores, bem como o acesso e uso de banheiro com independência, como responderam 20,4\% (150) dos professores, cuja adaptação de portas e colocação de barras de apoio nas paredes foram avaliadas como não essenciais, assim como não é essencial, para 13,0\% (96) dos professores, a construção de rampas com corrimão ou elevadores, de forma a facilitar a circulação em cadeira de rodas.

É possível inferir, a partir destes dados, que o direito em si do aluno com deficiência física de frequentar a universidade parece ser negado por alguns professores, pois o direito de ir e vir com independência não é considerado 
essencial para 10,0\% (74) dos professores em se tratando de pessoa com deficiência física, pois consideram não ser essencial a eliminação de barreira arquitetônica dificultadora ou impedidora de acesso a espaços coletivos, assim como outras necessidades desse aluno, como ilustrado no Gráfico 8.

\section{Demandas específicas essenciais aos alunos com deficiência física}

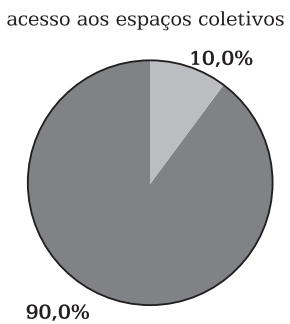

$90,0 \%$ reserva de vagas estacionamento

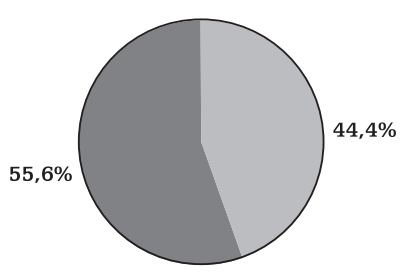

altura acessível equipamentos

adapt. portas apoio em banheiro

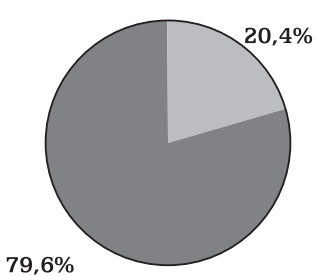

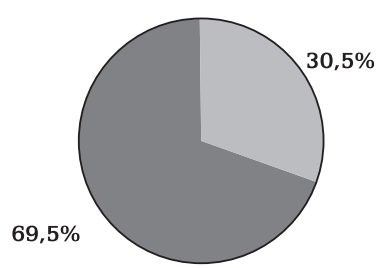

rampas e elevadores

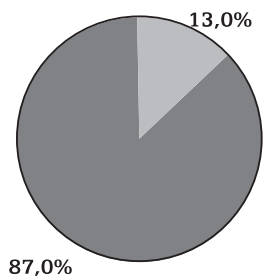

$87,0 \%$

Gráfico 8 - Necessidades Específicas do Graduando com Deficiência Física, na Perspectiva do Professor

Tabela 4A - Graduando com deficiência auditiva na universidade e suas demandas específicas, na perspectiva do professor

\begin{tabular}{|c|c|c|c|}
\hline \multirow{2}{*}{ Demandas do Graduando } & \multicolumn{2}{|c|}{ Essencial } & \multirow{2}{*}{ Total } \\
\hline & Sim & Não & \\
\hline $\begin{array}{l}\text { 1) Intérprete de língua de sinais, ao longo do } \\
\text { curso. }\end{array}$ & $\begin{array}{c}488 \\
(66,4 \%)\end{array}$ & $\begin{array}{c}247 \\
(33,6 \%)\end{array}$ & $\begin{array}{c}735 \\
(100 \%)\end{array}$ \\
\hline $\begin{array}{l}\text { 2) Intérprete de língua de sinais, em especial } \\
\text { quando da realização de provas ou da sua } \\
\text { revisão. }\end{array}$ & $\begin{array}{c}355 \\
(48,3 \%)\end{array}$ & $\begin{array}{c}380 \\
(51,7 \%)\end{array}$ & $\begin{array}{c}735 \\
(100 \%)\end{array}$ \\
\hline $\begin{array}{l}\text { 3) Complementação da avaliação da } \\
\text { aprendizagem do aluno, por meio de } \\
\text { intérprete de língua de sinais, em especial } \\
\text { se a avaliação for expressa em texto escrito. }\end{array}$ & $\begin{array}{c}321 \\
(43,7 \%)\end{array}$ & $\begin{array}{c}413 \\
(56,3 \%)\end{array}$ & $\begin{array}{c}734 \\
(100 \%)\end{array}$ \\
\hline $\begin{array}{l}\text { 4) Flexibilidade na correção das provas escritas, } \\
\text { valorizando o conteúdo semântico. }\end{array}$ & $\begin{array}{c}291 \\
(39,6 \%)\end{array}$ & $\begin{array}{c}444 \\
(60,4 \%)\end{array}$ & $\begin{array}{c}735 \\
(100 \%)\end{array}$ \\
\hline $\begin{array}{l}\text { 5) Informações aos professores, por meio de } \\
\text { materiais específicos, sobre a especificidade } \\
\text { linguística dos surdos. }\end{array}$ & $\begin{array}{c}448 \\
(61,0 \%)\end{array}$ & $\begin{array}{c}287 \\
(39,0 \%)\end{array}$ & $\begin{array}{c}735 \\
(100 \%)\end{array}$ \\
\hline
\end{tabular}

Mais preocupante é o não reconhecimento por parte dos professores de possíveis necessidades do aluno com deficiência auditiva ou surdo, 
cujo atendimento às suas demandas remete fundamentalmente à sala de aula, diferenciando-se, portanto, no geral, das demandas do aluno com deficiência física.

Há de se pontuar que o interesse e a mobilização para atender às necessidades de alguém decorrem do reconhecimento, em si, dessas necessidades, ou seja, de julgá-las como sendo essencial para a pessoa. Nesse sentido, os dados acima falam por si, pois, do total de 735 (97,7\%) dos 752 professores da amostra, obtiveram-se os seguintes resultados, no que diz respeito ao julgamento do professor como não sendo essencial para o aluno com deficiência auditiva:

a) flexibilidade na correção das provas escritas - 60,4\% (444) dos professores;

b) complementação da avaliação da aprendizagem com o auxílio de intérprete, em se tratando principalmente de prova escrita - 56,3\% (413) dos professores;

c) intérprete de língua de sinais, em especial quando da realização de provas ou de sua revisão - 51,7\% (380) dos professores;

d) intérprete de linguagem de sinais ao longo do curso - 33,6\% (247) dos professores.

Por fim, o atendimento ao aluno surdo implica conhecimentos das especificidades linguísticas desse aluno pelo professor, porém 39,0\% (287) dos professores não julgam essas informações como sendo essenciais.

A síntese do reconhecimento, pelo professor, de necessidades específicas do graduando com deficiência auditiva consta no Gráfico 9.

\section{Demandas específicas essenciais aos alunos com deficiência auditiva}
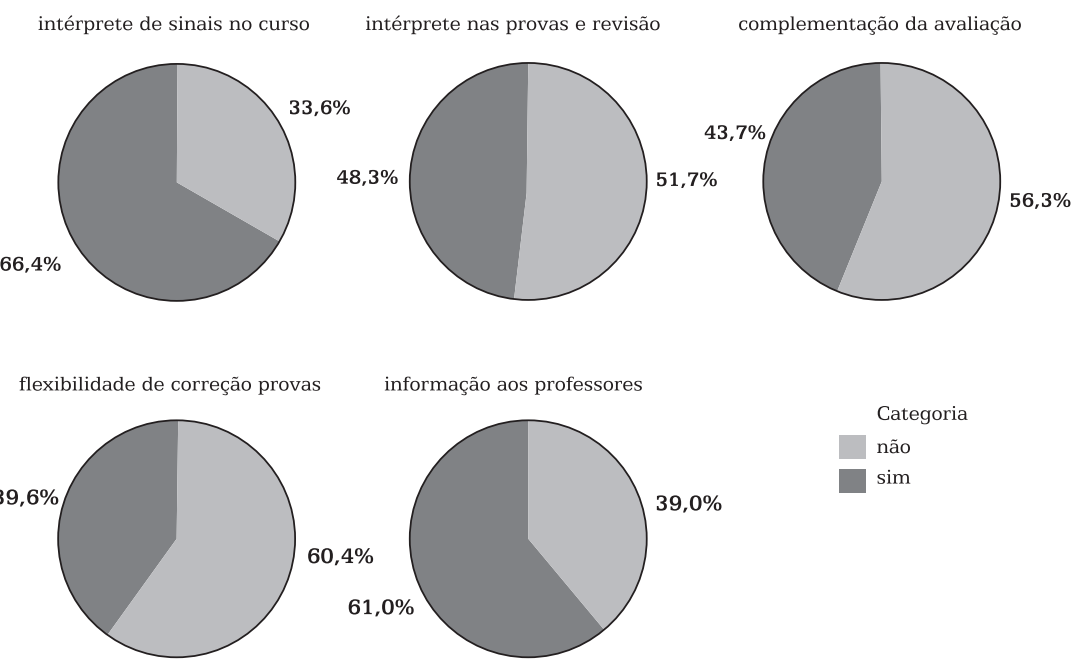

Gráfico 9 - Necessidades Específicas do Graduando com Deficiência Auditiva, na Perspectiva do Professor 
Em se tratando do terceiro grupo, graduandos com deficiência visual, a situação é similar à dos alunos acima, conforme a Tabela 4B.

Tabela 4B - Graduando com Deficiência Visual na Universidade e suas Demandas Específicas, na Perspectiva do Professor

\begin{tabular}{|c|c|c|c|}
\hline \multirow{2}{*}{ Demandas do Graduando } & \multicolumn{2}{|c|}{ Essencial } & \multirow{2}{*}{ Total } \\
\hline & Sim & Não & \\
\hline $\begin{array}{l}\text { 1) Máquina de datilografia braille, impressora } \\
\text { acoplada ao computador, sistema de síntese de } \\
\text { voz, scanner acoplado ao computador. }\end{array}$ & $\begin{array}{c}547 \\
(74,6 \%)\end{array}$ & $\begin{array}{c}186 \\
(25,4 \%)\end{array}$ & $\begin{array}{c}733 \\
(100 \%)\end{array}$ \\
\hline $\begin{array}{l}\text { 2) Gravador e fotocopiadora para ampliação de } \\
\text { textos. }\end{array}$ & $\begin{array}{c}348 \\
(47,5 \%)\end{array}$ & $\begin{array}{c}385 \\
(52,5 \%)\end{array}$ & $\begin{array}{c}733 \\
(100 \%)\end{array}$ \\
\hline 3) Lupas e réguas de leitura. & $\begin{array}{c}274 \\
(37,4 \%)\end{array}$ & $\begin{array}{c}458 \\
(62,6 \%)\end{array}$ & $\begin{array}{c}732 \\
(100 \%)\end{array}$ \\
\hline 4) Software de ampliação de tela. & $\begin{array}{c}383 \\
(52,3 \%)\end{array}$ & $\begin{array}{c}350 \\
(47,7 \%)\end{array}$ & $\begin{array}{c}733 \\
(100 \%)\end{array}$ \\
\hline $\begin{array}{l}\text { 5) Acervo bibliográfico em fitas de áudio e dos } \\
\text { conteúdos básicos, em braille, das disciplinas } \\
\text { do curso. }\end{array}$ & $\begin{array}{c}570 \\
(77,8 \%)\end{array}$ & $\begin{array}{c}163 \\
(22,2 \%)\end{array}$ & $\begin{array}{c}733 \\
(100 \%)\end{array}$ \\
\hline
\end{tabular}

De acordo com a avaliação de $733(97,7 \%)$ professores, do total de 752 (100\%) da amostra, não são consideradas essenciais, por ordem de grandeza, as necessidades do aluno quanto a:

a) lupas e réguas de leitura - 62,6\% (458);

b) gravador e fotocopiadora $-52,5 \%(385)$;

c) software de ampliação de tela - 47,7\% (350);

d) máquina de datilografia braille e outros - 25,4\% (186);

e) acervo bibliográfico em fitas de áudio e dos conteúdos básicos do curso em braille - 22,2\% (163).

Se a negação do reconhecimento de possíveis demandas do graduando com deficiência visual pode representar, em si, um dado desfavorável à vida acadêmica do aluno, há de se demarcar suas qualificações como essenciais por uma parte do professorado, conforme a Tabela 4B e o Gráfico 10.

Destaca-se desse modo, conforme a Tabela 4B e o Gráfico 10, que três das cinco necessidades qualificadas como sendo essenciais por $74,6 \%$ dos 733 professores ( $1^{\text {a }}$ necessidade), por $77,8 \%$ ( $5^{\mathrm{a}}$ necessidade) e por $52,3 \%$ dos professores ( $4^{\mathrm{a}}$ necessidade), enquanto sobre a $2^{\mathrm{a}}$ e $3^{\mathrm{a}}$ necessidades, como já colocado, recaíram os maiores percentuais de qualificação como não sendo essenciais ao graduando com deficiência visual. 


\section{Demandas específicas essenciais aos alunos com deficiência visual}
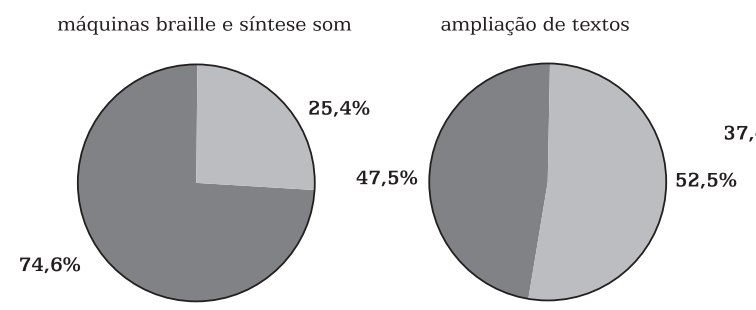

lupas e réguas de leitura

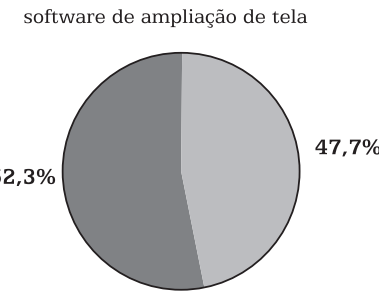

acervo bibliog. áudio e braille

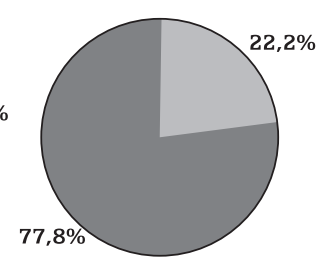

Categoria
não
sim

\section{Gráfico 10 - Necessidades Específicas do Graduando com Deficiência Visual, na Perspectiva do Professor}

Foram cruzadas algumas variáveis que interessavam à pesquisa, a fim de se determinar se há independência entre elas, isto é, se o fato de ser conhecida a ocorrência de uma delas leva a uma alteração na probabilidade de ocorrência da outra variável. O que se procurou inferir foi se professores com características diferentes têm ou não o mesmo olhar quanto à deficiência, à demanda do aluno com deficiência e à demanda do professor que lida com este aluno.

Ao se cruzar as variáveis "ter tido ou não aluno com deficiência" e "formação do professor", professores com formação na área de exatas apontaram, proporcionalmente, ter tido menos alunos com deficiência, enquanto que professores com formação na área de saúde relataram, proporcionalmente, ter tido mais alunos com deficiência $(P=0,002)$. Os alunos com deficiência talvez tenham predileção pela área de saúde, e os professores da área da saúde talvez estejam mais atentos aos casos de alunos com deficiência.

Em concordância com o dito acima, ao se cruzar as variáveis "ter tido ou não aluno com deficiência" e "unidade de origem do professor", constatou-se que professores das unidades Centro de Ciências Sociais e Aplicadas e Escola de Engenharia apontaram ter tido, proporcionalmente, menos alunos com deficiência $(\mathrm{P}=0,000)$. Outro resultado encontrado foi que professores da Faculdade de Direito e da Faculdade de Computação e Informática apontaram, proporcionalmente, ter tido mais alunos com deficiência.

Outro cruzamento que mostrou dependência entre as variáveis ( $\mathrm{P}=0,001)$ foi entre "ter tido ou não aluno com deficiência" e "tempo de 
docência no ensino superior". Como esperado, professores que lecionam há menos de cinco anos no ensino superior, tendo portanto menos tempo para a ocorrência do fato, apontaram ter tido, proporcionalmente, menos alunos com deficiência.

Ao se estudar a relação entre "ter tido ou não aluno com deficiência" e nota 1 atribuída à "adaptação em procedimentos de avaliação do ensino-aprendizagem", foi obtida uma relação de dependência entre elas $(\mathrm{P}=0,032)$. Estranhamente, professores que atribuíram nota 1 à adaptação em procedimentos de avaliação do ensino-aprendizagem apontaram, proporcionalmente, ter tido mais alunos com deficiência, revelando que sua experiência com alunos deficientes não os levou a valorizar a necessidade de adaptação em procedimentos de avaliação para esses alunos.

Já professores que nunca tiveram alunos com deficiência física marcaram proporcionalmente menos a condição de acesso aos espaços de uso coletivo por meio da eliminação de barreira arquitetônica como condição essencial, inferindo-se uma relação de dependência entre as variáveis "ter tido ou não aluno com deficiência" e marcar a condição de acesso aos espaços de uso coletivo por meio da eliminação de barreira arquitetônica como condição essencial $(P=0,005)$. Este resultado era previsível, uma vez que o fato de nunca ter tido aluno deficiente colabora com a falta de sensibilidade para a demanda deste aluno. O mesmo se repete em relação à condição de reserva de vagas em estacionamentos nas proximidades da UA como condição essencial $(\mathrm{P}=0,001)$. Professores que nunca tiveram alunos com deficiência física marcaram, proporcionalmente, menos a condição de reserva de vagas em estacionamentos nas proximidades da Universidade como condição essencial.

Com relação aos professores que já tiveram alunos com deficiência visual, estes marcaram proporcionalmente mais a necessidade de gravador e fotocopiadora para ampliação de textos $(\mathrm{P}=0,001)$ e a necessidade de lupas e réguas de leitura $(P=0,000)$ como condições essenciais. Para as outras necessidades, não houve diferenças significantes na proporção marcada pelos professores que tiveram ou que não tiveram alunos com deficiência visual.

Ao se estudar a relação entre "ter tido ou não aluno com deficiência auditiva" e marcar a necessidade de intérprete de língua de sinais ao longo do curso como condição essencial, foi obtida uma relação de dependência entre elas ( $\mathrm{P}=0,027)$. Professores que tiveram alunos com deficiência auditiva marcaram proporcionalmente mais a necessidade de intérprete de língua de sinais ao longo do curso como condição essencial, o que mostra sua sensibilização quanto a esta questão. Para as outras condições, não houve diferenças significantes na proporção marcada pelos professores que tiveram ou que não tiveram alunos com deficiência auditiva.

Quanto à demanda dos professores, os que não tiveram alunos com alguma deficiência requisitaram proporcionalmente mais que os demais 
uma capacitação ( $P=0,027$ ) (cf. Tabela 5), retratando que não se sentem seguros para assumir tal tarefa.

A coerência na resposta do questionário também foi encontrada nos testes de independência entre nota atribuída à eliminação de barreira arquitetônica e adaptação de espaço físico e marcar a alternativa de demanda específica de acesso aos espaços de uso coletivo por meio da eliminação de barreira arquitetônica $(\mathrm{P}=0,000)$ e de demanda específica de reserva de vagas em estacionamentos nas proximidades da universidade $(P=0,015)$. Professores que atribuíram notas mais baixas (1 e 2) para a eliminação de barreira arquitetônica e adaptação de espaço físico marcaram proporcionalmente menos a alternativa de demanda específica de acesso aos espaços de uso coletivo por meio da eliminação de barreira arquitetônica, enquanto professores que atribuíram a nota mais alta (5) para a eliminação de barreira arquitetônica e adaptação de espaço físico marcaram proporcionalmente mais a alternativa de demanda específica de reserva de vagas em estacionamentos nas proximidades da UA.

O conjunto das análises até aqui apresentadas denota que, em detrimento das tardias conquistas legais desse segmento da população, o reconhecimento de suas necessidades ainda não atingiu todo o professorado da universidade, cabendo ações diretas por parte da instituição, no sentindo de informar e sensibilizar a todos.

Esta afirmativa pode ser sustentada nos dados da análise de 53,9\% dos questionários e reafirmada pelo desinteresse pelo tema por parte de 46,1\% dos professores que devolveram o questionário em branco ou não o retiraram, mesmo constando em sua introdução que um dos objetivos da pesquisa era "[...] oferecer subsídios para a implementação de futuras ações afirmativas e política institucional favorecedoras do aprimoramento das condições de permanência desse alunado".

\section{Outras condições especiais do alunado}

Se a condição de deficiente pode implicar diferenças significativas, há outras condições especiais do graduando apontadas por professores que não são decorrentes da deficiência. Desta feita, 74 professores no ensino superior e 51 na UA confirmaram essa experiência (cf. Tabela 2), embora nem todos tenham especificado quais as outras condições especiais dos graduandos.

No conjunto das 66 condições especiais apontadas, quer no ensino superior, quer na UA, há de se destacar os "diagnósticos", cabendo interrogar se são reais ou uma tendência do professorado, inclusive da educação básica, de atribuir/rotular determinados alunos.

As condições especiais apontadas foram organizadas em: transtornos psiquiátricos, problemas emocionais, deficiências, problemas comportamentais e de aprendizagem e outros, conforme o Quadro 1. 
Quadro 1 - Condições Especiais Outras do Graduando, segundo os Professores

\begin{tabular}{|c|c|c|}
\hline Condições & Especificações & Quantidade \\
\hline Transtornos psiquiátricos & $\begin{array}{l}\text { Bipolar; esquizofrenia, } \\
\text { sofrimento psíquico intenso, } \\
\text { transtorno mental, distúrbio } \\
\text { mental, doença psiquiátrica, } \\
\text { transtornos psicopatológicos e } \\
\text { mentais. }\end{array}$ & 17 \\
\hline Problemas emocionais & $\begin{array}{l}\text { Síndrome do pânico, } \\
\text { depressão, distúrbio } \\
\text { emocional acentuado. }\end{array}$ & 07 \\
\hline Deficiências & $\begin{array}{l}\text { Deficiência mental, deficiência } \\
\text { psicológica, deficiência cognitiva, } \\
\text { deficiência intelectual, deficiência } \\
\text { neurológica. }\end{array}$ & 11 \\
\hline $\begin{array}{l}\text { Problemas } \\
\text { comportamentais e de } \\
\text { aprendizagem }\end{array}$ & $\begin{array}{l}\text { Déficit de atenção, } \\
\text { hiperatividade, dislexia, } \\
\text { dificuldades comportamentais } \\
\text { severas. }\end{array}$ & 27 \\
\hline Outros & $\begin{array}{l}\text { Asmático, daltonismo, alcoolismo } \\
\text { e consumo de drogas. }\end{array}$ & 04 \\
\hline & Total & 66 \\
\hline
\end{tabular}

Demandas docentes por apoios da universidade

Encerra-se a apresentação e discussão dos dados coletados junto aos professores trazendo-se sugestões ou demandas de 453 professores (60,3\% dos 752 sujeitos da amostra) referentes ao tipo de apoio que a universidade poderia oferecer-lhes de forma a favorecer o atendimento e a permanência do graduando com deficiência.

Por se tratar de questão aberta e sujeita a mais de uma indicação pelo professor, deparou-se com imenso volume de dados, em parte genéricos (por exemplo, "cursos") e outros específicos (por exemplo, "curso de braille" e de "libras") ou apoios indicados para os professores e apoios para o aluno.

Desta feita, constam na Tabela 5 os apoios indicados de forma genérica. 
Tabela 5 - Demandas Genéricas de Professores: Apoio para Atender às Necessidades do Graduando com Deficiência

\begin{tabular}{|c|c|c|c|c|}
\hline Tipo de Apoio & \multicolumn{2}{|c|}{ Indicado } & \multicolumn{2}{|c|}{ Não Indicado } \\
\hline 1) Palestra & 40 & $(8,8 \%)$ & 414 & $(91,2 \%)$ \\
\hline 2) Cursos & 157 & $(34,7 \%)$ & 296 & $(65,3 \%)$ \\
\hline 3) Capacitação & 144 & $(31,8 \%)$ & 309 & $(68,2 \%)$ \\
\hline 4) Workshop & 49 & $(10,8 \%)$ & 404 & $(89,2 \%)$ \\
\hline 5) Orientação & 222 & $(49,0 \%)$ & 231 & $(51,0 \%)$ \\
\hline $\begin{array}{l}\text { 6) Flexibilizar procedimentos de } \\
\text { avaliação }\end{array}$ & 119 & $(26,3 \%)$ & 333 & $(73,7 \%)$ \\
\hline 7) Flexibilizar metodologias & 130 & $(28,7 \%)$ & 323 & $(71,3 \%)$ \\
\hline 8) Apoio ao aluno & 116 & $(25,6 \%)$ & 337 & $(74,4 \%)$ \\
\hline 9) Respeito e compreensão ao aluno & 50 & $(11,0 \%)$ & 403 & $(89,0 \%)$ \\
\hline 10) Adaptação do espaço físico & 23 & $(5,1 \%)$ & 429 & $(94,9 \%)$ \\
\hline
\end{tabular}

Observa-se que a expectativa por orientação $(49,0 \%)$, cursos $(34,7 \%)$ e capacitação $(31,8 \%)$ foram os apoios indicados com maior frequência, com baixa frequência para workshop (10,8\%), palestra $(8,8 \%)$ e adaptações do espaço físico (5,1\%). O professor propõe ainda ações circunscritas ao âmbito da sala de aula, o que possivelmente revela seu desconhecimento em como realizá-las: flexibilização de metodologias (28,7\%) e de procedimentos de avaliação (26,3\%). O apoio ao aluno, embora genérico, foi indicado por 25,6\% dos professores e respeito e compreensão ao aluno, por 11,0\%.

Os dez apoios acima indicados e suas frequências estão representados nos Gráficos 11A e 11B.

Sugestões de apoio entre os que manifestaram suas opinióes
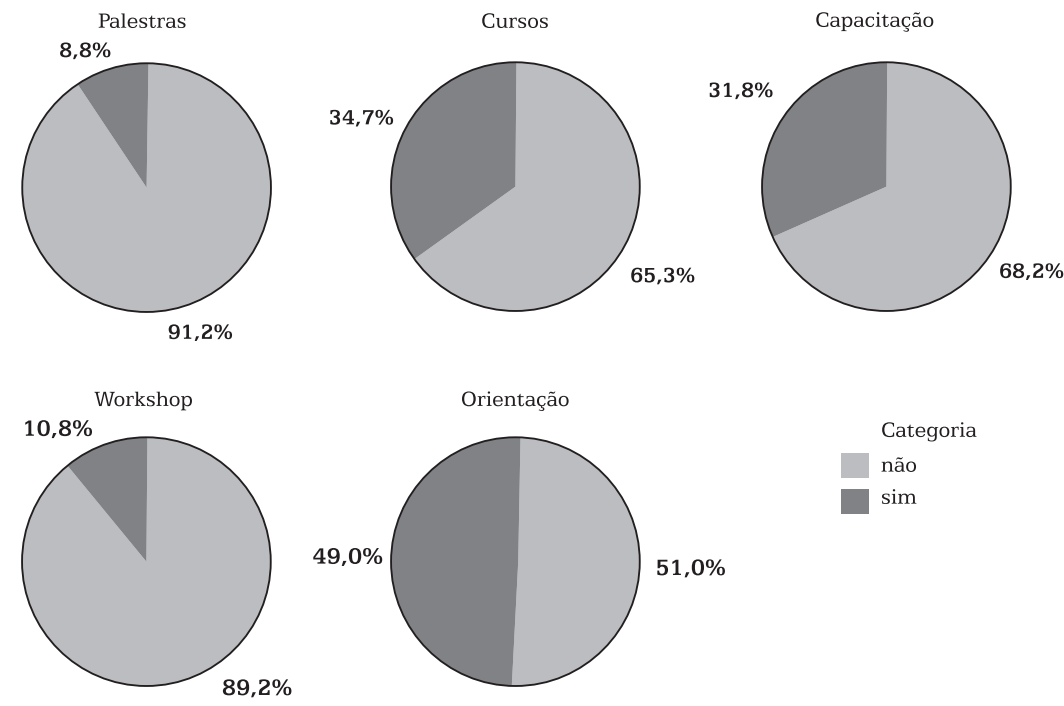

Gráfico 11A - Demandas de Professores por Apoios Genéricos 
Outras sugestões de apoio entre os que manifestaram suas opinióes
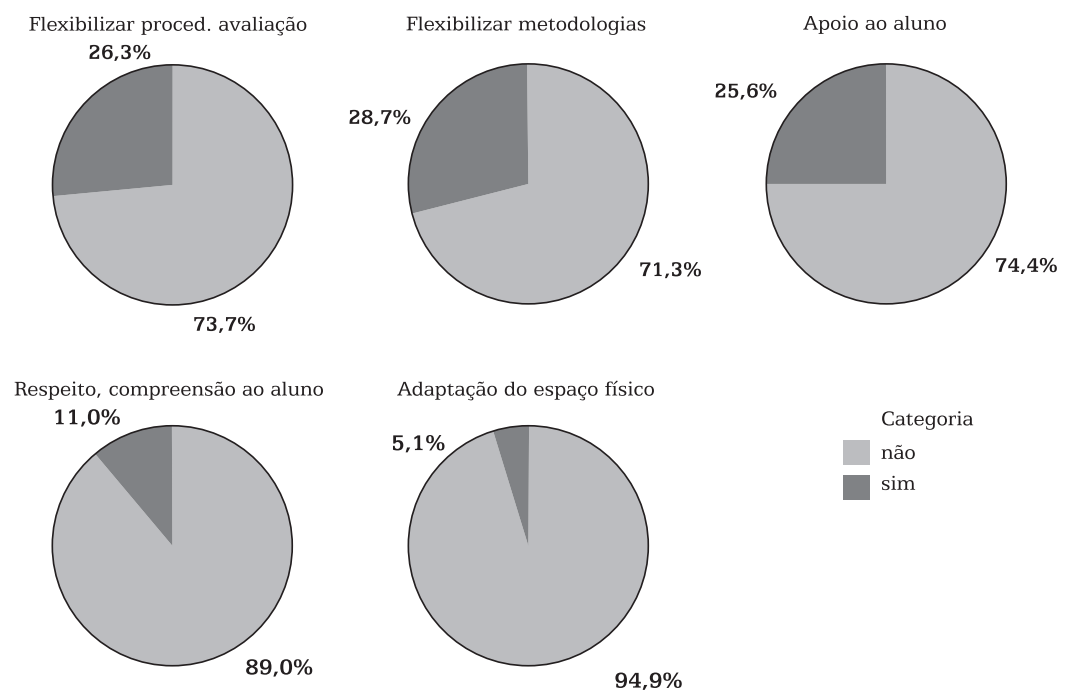

\section{Gráfico 11B - Demandas de Professores por Apoios Genéricos}

Na sequência, e na tentativa de ser fiel aos dados coletados, apresentam-se as ações específicas indicadas por 199 dos 453 professores, sendo que algumas dessas ações podem ser tomadas como desmembramento dos apoios configurados como gerais (cf. Tabela 5 e Gráficos 11A e 11B).

No Quadro 2 constam as especificações de ações de apoio para o professor e, no Quadro 3, as ações de apoio indicadas pelos professores para o graduando com deficiência.

\section{Quadro 2 - Ações Específicas de Apoio ao Professor}

\begin{tabular}{|c|c|}
\hline Ações de Apoio & Descrição \\
\hline 1) Cursos & $\begin{array}{l}\text { Libras; braille; didática especializada; formação específica } \\
\text { para cada tipo de dependência; especificidade linguística } \\
\text { do aluno surdo. }\end{array}$ \\
\hline 2) Capacitação & $\begin{array}{l}\text { Para funcionários e professores; educação inclusiva } \\
\text { e mudança social; conduta com alunos surdos; } \\
\text { conscientização; informação sobre as especificidades das } \\
\text { deficiências mais frequentes e sobre suas possibilidades e } \\
\text { limites; como tratar o deficiente. }\end{array}$ \\
\hline $\begin{array}{l}\text { 3) Criação de núcleo } \\
\text { multidisciplinar }\end{array}$ & $\begin{array}{l}\text { Assessoria especializada e permanente aos professores, } \\
\text { fórum permanente de educação inclusiva; combate ao } \\
\text { preconceito e ao medo; campanhas educativas sobre inclusão. }\end{array}$ \\
\hline $\begin{array}{l}\text { 4) Alteração } \\
\text { funcional e } \\
\text { estrutural }\end{array}$ & $\begin{array}{l}\text { Horários especiais: para atendimento aos alunos e para } \\
\text { provas; horário remunerado para reuniões entre os } \\
\text { docentes; informação prévia da presença de alunos com } \\
\text { deficiência para planejamento de procedimentos adequados; } \\
\text { redução do número de alunos em sala de aula com aluno } \\
\text { com deficiência; remuneração extra para dedicação ao } \\
\text { aluno; salário diferenciado. }\end{array}$ \\
\hline 5) Suporte material & $\begin{array}{l}\text { Material didático; material informativo sobre as } \\
\text { adaptações nos campi; informações/orientações } \\
\text { específicas via internet. }\end{array}$ \\
\hline
\end{tabular}




\title{
Quadro 3 - Ações Específicas de Apoio ao Graduando
}

\begin{tabular}{|c|c|}
\hline Ações de Apoio & Descrição \\
\hline $\begin{array}{l}\text { 1) Acompanhamento } \\
\text { por especialistas }\end{array}$ & $\begin{array}{l}\text { Processo de ensino-aprendizagem; atendimento } \\
\text { psicológico; atendimento pedagógico; atendimento } \\
\text { psicopedagógico. }\end{array}$ \\
\hline 2) Salas especiais & Na biblioteca, para pesquisa. \\
\hline 3) Intérprete & Para TCC e iniciação científica. \\
\hline $\begin{array}{l}\text { 4) Monitoria e } \\
\text { tutoria }\end{array}$ & Auxílio às necessidade especiais do aluno. \\
\hline 5) Avaliação & $\begin{array}{l}\text { Médica, para especificar as limitações do aluno; } \\
\text { avaliação pedagógica prévia do aluno com DA e DV; } \\
\text { avaliação do ensino-aprendizagem. }\end{array}$ \\
\hline $\begin{array}{l}\text { 6) Criação } \\
\text { de Núcleo } \\
\text { multidisciplinar }\end{array}$ & Assessoria a alunos. \\
\hline 7) Suporte material & $\begin{array}{l}\text { Gravação das aulas ministradas (DV); DVDs } \\
\text { específicos (DV), material didático em braille. }\end{array}$ \\
\hline
\end{tabular}

Se no conjunto dos apoios indicados evidenciam-se ações relevantes tanto para o docente quanto para o graduando, há professores que negam qualquer iniciativa institucional:

\begin{abstract}
A UA já fornece quase todo tipo de apoio; não acredito que os professores devem receber preparação específica para receber esses alunos; nenhum apoio, pois o aluno é que deve se adaptar ao universo comum ou recorrer a instituições especializadas; deve partir do próprio aluno ou de seu representante legal ou procurador.
\end{abstract}

Há professores que, ao sugerir, revelam a não diferenciação entre deficiência e doença: "plantão de enfermeiros; primeiros socorros; flexibilidade maior em relação às faltas do aluno; suporte jurídico com relação ao tipo de formação possível e permitida ao aluno deficiente em caso de ampla limitação". Tais posições, em si, sugerem a relevância de ações informativas, pois implicam representações da pessoa com deficiência, mescladas por conteúdos internos alimentadores de barreiras interpessoais presentes nos espaços sociais, entre eles o da universidade.

As demandas docentes por apoio da universidade informam a priori aos dirigentes da UA os caminhos iniciais para planejar ações em prol de uma permanência mais qualificada dos graduandos com deficiência em seus cursos, independentemente de terem apontado demandas gerais ou específicas, inclusive reconhecem que o apoio ao aluno também é uma das necessidades.

A informação é o caminho para romper com mitos que povoam o imaginário popular e que adentraram a universidade, pois professores solicitaram capacitação para saber "como tratar o deficiente", ou sugeriram "horários especiais para atender aos alunos e para as provas, remuneração para reuniões específicas, redução do número de alunos em 
classe integrada por aluno com deficiência", e, mais, "remuneração extra ou salário diferenciado para o professor" (cf. Quadro 2). Na indicação de apoio ao graduando, cabe destacar a "avaliação médica para especificar as limitações do aluno", e outras, como indicado no Quadro 3.

Pode-se inferir dos dados acima que as barreiras enfrentadas por graduandos com deficiência, tenham ou não necessidades diferenciadas dos demais alunos, são de natureza diversa, e algumas dessas barreiras são alimentadas por mitos sobre as deficiências presentes nos diferentes espaços do campo social e que não são superadas por dispositivos legais, área com avanços importantes.

As barreiras enfrentadas por professores, por sua vez, são indicativos de suas necessidades imediatas, que são de extrema relevância quando se considera que o corpo docente é relativamente jovem, portanto, com probabilidade de ter outros alunos com deficiência em suas trajetórias profissionais. Informá-los e apoiá-los em suas demandas é responsabilidade de todos, em especial da universidade, pois só assim caminhar-se-á em direção à construção de práticas educacionais e pedagógicas mais inclusivas, reveladoras do potencial acadêmico de todos os alunos, tenham ou não deficiência.

\section{Considerações finais}

A educação inclusiva no ensino superior constitui-se, neste atual momento, um dos pontos fundamentais de discussões e preocupações dos atores envolvidos no cenário da educação brasileira, em conformidade com as políticas de inclusão socioeducacional voltadas a pessoas com deficiência. Entretanto, conforme foi anteriormente apontado, estudos sobre a temática em questão são ainda incipientes em nosso meio, e as poucas pesquisas encontradas na revisão da literatura mostraram que elas se basearam em entrevistas com pequeno número de atores, quer fossem com alunos, quer com professores, coordenadores e/ou diretores.

Acredita-se que a relevância desta pesquisa repousa no expressivo número de professores participantes, ainda que, dos 1.394 professores dos dois campi, 752 tenham respondido os questionários.

Pesquisas realizadas em outras instituições de ensino superior no Brasil que nos serviram de base apontaram, em seu conjunto, a premente necessidade de quebra de barreiras arquitetônicas, concomitantemente com a busca de superação de barreiras atitudinais, estas sabidamente com maior dificuldade de enfrentamento, pois demandam mudanças no âmbito de valores individuais e coletivos no que se refere à superação de preconceitos em relação a diferenças do alunado em questão.

Projetar e investir na construção de uma universidade inclusiva é um processo complexo e gradativo, porém tarefa urgente, pois, do contrário, manter-se-á o hiato entre o discurso teórico, os dispositivos legais e as práticas.

Os resultados desta pesquisa apontaram, em conformidade com a literatura, a necessidade de se desenvolver, no âmbito das universidades, 
programas de preparação de professores e profissionais da educação para atuarem ante à diversidade, tanto em seus cursos de graduação como em programas de formação continuada. Seus resultados poderão, principalmente, servir de alicerce para o delineamento de uma proposta de implementação de serviço de apoio aos graduandos com deficiência e de suporte ao corpo docente da UA, instituindo-se, no âmbito da universidade, um serviço de apoio à comunidade acadêmica que possa congregar as ações existentes, mas que se encontram dispersas, tanto no que se refere a questões de acessibilidade física como aquelas relativas à inclusão social baseada em atitudes favoráveis à diversidade humana, com repercussões em todos os espaços e ações institucionais, em especial nas salas de aula.

\section{Referências bibliográficas}

\section{ASSOCIAÇÃO BRASILEIRA DE NORMAS TÉCNICAS (ABNT). NBR} 9050:2004. Acessibilidade a edificações, mobiliário, espaços e equipamentos urbanos. Rio de Janeiro, 2004. Disponível em: < http:// portal.mj.gov.br/corde/arquivos/ABNT/NBR9050-31052004.pdf $>$.

BEYER, H. O. A educação inclusiva: incompletudes escolares e perspectivas de ação. Cadernos de Educação Especial, Santa Maria, n. 22, 2003. Disponível em: < http://www.ufsm.br/ce/revista/ ceesp/2003/02/a3.html>. Acesso em: 18 jul. 2008.

. Da integração escolar à educação inclusiva: implicações pedagógicas. In: BAPTISTA, C. R. (Org.) Inclusão e escolarização: múltiplas perspectivas. Porto Alegre: Mediação, 2006. p. 73-81.

BRASIL. Ministério da Educação. Portaria no 1.793/1994. Brasília. Disponível em: <http://portal.mec.gov.br/seesp/arquivos/pdf/port1793.pdf>.

. Portaria no 3.284/2003. Brasília. Disponível em: <http:// portal.mec.gov.br/seesp/arquivos/pdf/port3284.pdf>.

BRASIL. Decreto no 5.626/2005. Regulamenta a Lei no 10.436, de 24 de abril de 2002, que dispõe sobre a Língua Brasileira de Sinais - Libras, e o art. 18 da Lei n 10.098, de 19 de dezembro de 2000. Brasília. Disponível em: < http://www.planalto.gov.br/ccivil_03/_ato20042006/2005/decreto/d5626.htm>.

BUENO, J. G. S. As políticas de inclusão escolar: uma prerrogativa da Educação Especial? In: BUENO, José Geraldo S.; MENDES, Geovana M. Lunardi; SANTOS, Roseli Albino (Orgs.). Deficiência e escolarização: novas perspectivas de análise. Araraquara: Junqueira \& Marim; Brasília: Capes, 2008. p. 43-63. 
BOLFARINE, H.; BUSSAB, W. O. Elementos de amostragem. São Paulo: Edgard Blücher, ABE, 2005. (Projeto Fisher, 2).

CASTANHO, D. M.; FREITAS S. N. Inclusão e prática docente no ensino superior. Revista Educação Especial, Santa Maria, n. 27, 2005. Disponível em: <http://www.ufsm.br/ce/revista/ceesp/2006/01/ a6.html>. Acesso em: 19 jun. 2008.

EIDELWEIN, M. P. Pedagogia universitária voltada à formação de professores na temática da inclusão. Revista Educação Especial, Santa Maria, n. 26, 2005. Disponível em: < http://www.ufsm.br/ce/revista/ ceesp/2005/02/a9.html>. Acesso em: 18 jul. 2008.

FERREIRA, S. L. Diversidade e ensino superior: a Universidade Estadual de Londrina na construção de uma "sociedade para todos". In: MARQUEZINE, Maria Cristina et al. (Orgs.). Inclusão. Londrina: Eduel, 2003. p. 269-281.

JESUS, D. M. Inclusão escolar, formação continuada e pesquisa-ação colaborativa. In: BAPTISTA, C. R. (Org.). Inclusão e escolarização: múltiplas perspectivas. Porto Alegre: Mediação, 2006. p. 95 -106.

MARTINS, L. A. R. Inclusão escolar: algumas notas introdutórias. In: MARTINS, L. A. R. et. al. (Org.). Inclusão: compartilhando saberes. Petrópolis: Vozes, 2006. p. 17-26.

MICHELS, L. R. F.; DELLECAVE, M. do R. O que os professores têm a dizer sobre a educação inclusiva na universidade. Contrapontos, Itajaí, v. 5, n. 2, p. 469-481, set./dez. 2005.

MOREIRA, H. F.; MICHELS, L. R.; COLOSSI, N. Inclusão educacional para pessoas portadoras de deficiência: um compromisso com o ensino superior. Escritos sobre educação, Ibireté, v. 5, n. 1, p. 1925, jun. 2006. Disponível em: < http://pepsic.bvsalud.org/scielo. php?pid=S1677-98432006000100001\&script=sci_arttext $>$.

MOREIRA, L. C. A universidade e o aluno com necessidades educativas especiais: reflexões e proposições. In: RIBEIRO, Maria Luiza; BAUMEL, Roseli Cecília Rocha Carvalho. Educação especial: do querer ao fazer. São Paulo: Avercamp, 2003. p. 81-93.

. In(ex)clusão na universidade: o aluno com necessidades educacionais especiais em questão. Revista Educação Especial, Santa Maria, n. 25, p. 37-47, 2005. Disponível em: <http://cascavel.ufsm.br/ revistas/ojs-2.2.2/index.php/educacaoespecial/article/view/4902>.

PACHECO, R. V.; COSTAS F. A. T. O processo de inclusão de acadêmicos com necessidades educacionais especiais na Universidade Federal de 
Santa Maria. Revista Educação Especial, Santa Maria, n. 27, 2005.

Disponível em: <http://www.ufsm.br/ce/revista/ceesp/2006/01/a12.

htm>. Acesso em: 18 jun. 2008.

PAULA, Sonia Nascimento de; CARVALHO, José Oscar Fontanini de. Acessibilidade à informação: proposta de uma disciplina para cursos de graduação na área de biblioteconomia. Ciência da Informação [online], v. 38, n. 3, p. 64-79, 2009. Disponível em <http://www.scielo.br/scielo. php?script $=$ sci_arttext\&pid $=$ S010019652009000300005\&lng $=$ pt\&nrm =iso $>$. ISSN 0100-1965. doi: 10.1590/S0100-19652009000300005. Acesso em: 15 abr. 2011.

PATTO, M. H. S. Políticas atuais de inclusão escolar: reflexão a partir de um recorte conceitual. In: BUENO, J. G. S.; MENDES, G. M. L.; SANTOS, R. A. (Orgs.). Deficiência e escolarização: novas perspectivas de análise. Araraquara: Junqueira \& Marim; Brasília: Capes, 2008, p. 25-42.

REIS, E.; FERREIRA, M. Métodos quantitativos I. Lisboa: Silabo, 2000.

RODRIGUES, D. A inclusão na universidade: limites e possibilidades da construção de uma universidade inclusiva. Cadernos de Educação Especial, Santa Maria, n. 23, 2004. Disponível em: < http://www.ufsm. br/ce/revista/ceesp >. Acesso em: 25 jun. 2008.

RODRIGUES, D. (Org.). Inclusão e educação: doze olhares sobre a educação inclusiva. São Paulo: Summus, 2006.

\section{SIEGEL, S.; CASTELLAN JUNIOR., N. J. Estatística não-paramétrica} para ciências do comportamento. 2. ed. Porto Alegre: Bookman, 2008.

VITALIANO, C. R. Concepções de professores universitários da área de educação e do ensino regular sobre o processo de integração de alunos especiais e a formação de professores. 2002. 308f. Tese (Doutorado em Educação) - Universidade Estadual Paulista, Faculdade de Filosofia e Ciências, Marília, 2002.

Ani Martins Silva, doutora em Educação pela Pontifícia Universidade Católica de São Paulo (PUC-SP), é professora do curso de Pedagogia do Centro de Ciências e Humanidades da Universidade Presbiteriana Mackenzie.

animartins@mackenzie.br

Raquel Cymrot, mestre em Estatística pela Universidade de São Paulo (USP), é professora da Escola de Engenharia da Universidade Mackenzie. raquelc@mackenzie.br 
Demandas de docentes do ensino superior para a formação de alunos com

Maria Eloisa Famá D’Antino, doutora em Psicologia Escolar e do Desenvolvimento Humano pela Universidade de São Paulo (USP), é professora do Centro de Ciências Biológicas e da Saúde e do Programa de Pós-Graduação em Distúrbios do Desenvolvimento.

dantino@mackenzie.br

Recebido em 19 de abril de 2011.

Aprovado em 18 de abril de 2012. 